\title{
Alpha factor determination in a pilot scale sidestream shortcut nitrification process
}

\author{
Mateusz Muszyński-Huhajło ${ }^{1, *}$, Stanisław Miodoński ${ }^{1}$, and Katarzyna Rucka ${ }^{1}$ \\ ${ }^{1}$ Faculty of Environmental Engineering, Wroclaw University of Science and Technology, \\ Plac Grunwaldzki 9, 50-377 Wroclaw, Poland
}

\begin{abstract}
Aeration is considered as one of the most energy consuming process during the wastewater treatment process and its proper design plays important role in further overall wastewater treatment plant energy balance. Design guidelines for aeration systems in mainstream treatment of municipal wastewater are well known, however there are some doubts about transferring them to sidestream treatment installations. Different process rates, reactors geometry and treated medium composition may significantly affect aeration efficiency and this case must be verified. Series of alpha factor measurements were performed during start-up of shortcut nitrification process of real reject water from sludge dewatering. Surprisingly, observed alpha factor values were close and higher than 1.0 which is uncommon for such aeration devices as used in this study. Paper presents discussion of potential reasons of observed facts and outlines directions of further work.
\end{abstract}

\section{Introduction}

Role of oxygen in natural water purification processes was known long before society ecological awareness turned their attention to the need of wastewater treatment. Flowing water bodies, i.e. swift streams or rivers were considered as source of high quality water for centuries. First attempts to improve quality of wastewater discharged into natural waters were meant to imitate those natural processes. As wastewater treatment technologies developed and obtained treatment process rates intensified, oxygen consumption rose making primitive aeration methods insufficient. Different aeration methods and available equipment evolved significantly in the past 100 years along with development of wastewater treatment technologies. Currently, aeration process is responsible for c.a. $30-75 \%$ of energy consumption in activated sludge process, which is the most common wastewater treatment method in the world [1]. Energy efficiency of aeration systems has become one of the main object of interest in the recent years, especially considering efforts undertaken to achieve energy-neutrality of WWTPs. In face of these facts, proper aeration design and operational principles became subject of many studies. Influence of wastewater composition, aeration tank geometry and hydraulics has been verified among many other factors affecting the efficiency of oxygen transfer [2]. Despite huge amount of available knowledge, aeration design principles focus on facilities used to treat municipal wastewater in conventional

\footnotetext{
*Corresponding author: mateusz.muszynski-huhajlo@pwr.edu.pl
} 
activated sludge systems. In recent years, increasing popularity of sidestream treatment technologies, created new challenge in case of aeration systems in these solutions. It is unsure, whether design practice known from mainstream air distribution systems is fully transferable to sidestream processes, i.e. shortcut nitrification or partial nitritation reactor in a two-step deammonification process [3]. Reject water from sludge dewatering has way different composition than municipal wastewater which may affect oxygen transfer in systems treating this medium. Moreover, sidestream systems can be also different in other aspects, such as higher nitrification process rates, biomass concentration level and relatively small reactor volume, resulting in the final dimensions of the aeration tank.

Alpha factor in sidestream reject water, as one of the fundamental parameters determining aeration system, was investigated in this study. Potential differences can significantly influence designed aeration systems efficiency or may be helpful in optimization of existing facilities. Paper presents alpha factor measurements performed during shortcut nitrification process start-up performed in a pilot scale reactor treating real reject water, which was probably the first attempt to experimentally determine this value in a sidestream treatment installation.

\subsection{Alpha factor}

Diffusers, as one of the most crucial part of each aeration system, has different characteristics, depending on many factors (i.e. released bubble size, material used etc.). To compare different types of this devices and design aeration system calculations, manufacturers provide information about their oxygen transfer efficiency (OTE) measured in clean water conditions. Unfortunately, in typical process conditions, OTE value drops significantly, lowering the overall aeration efficiency. To determine actual values achieved in operating conditions, several correction factors are used. One of them is the alpha factor, which allows to include the impact of substances present in the aerated medium. It can be identified as a ratio of $\mathrm{K}_{\mathrm{L}} \mathrm{a}$ value in polluted medium and $\mathrm{K}_{\mathrm{L}}$ a value in clean water (Eq. 1).

$$
\alpha=\frac{K_{L} a_{p m}}{K_{L} a_{c w}}
$$

where:

$K_{L} a_{p m}-$ volumetric mass transfer coefficient determined experimentally in process medium aerated during normal operation, time ${ }^{-1}$.

$K_{L} a_{c w}$-volumetric mass transfer coefficient determined experimentally in clean water (value provided by the manufacturer for each brand-new diffusor), time ${ }^{-1}$.

During the design process of a new aeration system, normal practice is to assume alpha factor in around 0.8, which was considered in designer's opinion as "universal". However, Rosso and Stenstrom [4] reports, that in series of alpha factor measurements performed on various wastewater treatment plants with fine pore aerators results varied from 0.2 to 0.8 . Such huge range of observed $\alpha$ implies serious doubts about assuming this crucial parameter without any measurements. Big differences between designed and real alpha may cause serious operational problems of the aeration system when this parameter is undervalued or oversizing the installation, which will additionally increase the investment costs of the whole operation. 


\section{Materials and methods}

\subsection{Experimental set-up}

\subsubsection{Pilot scale SBR}

Start-up was performed in a $150 \mathrm{~L}$ SBR treating real reject-liquor from digested sludge dewatering. Reactor was operated at predefined time cycles, consisting of filling, mixing with aeration, sedimentation, decantation phases. Reactor was equipped with number of sensors connected to SCADA system providing parental control of following parameters: temperature, $\mathrm{pH}, \mathrm{DO}$ level, filling/decanting volume and mixing intensity. Aeration system consisted of single membrane fine-pore diffuser (Rechau RAUBIOXON 200) attached at the bottom of the reactor connected to air blower with automatic airflow controller. Reactor schematics was shown in the Figure 1.

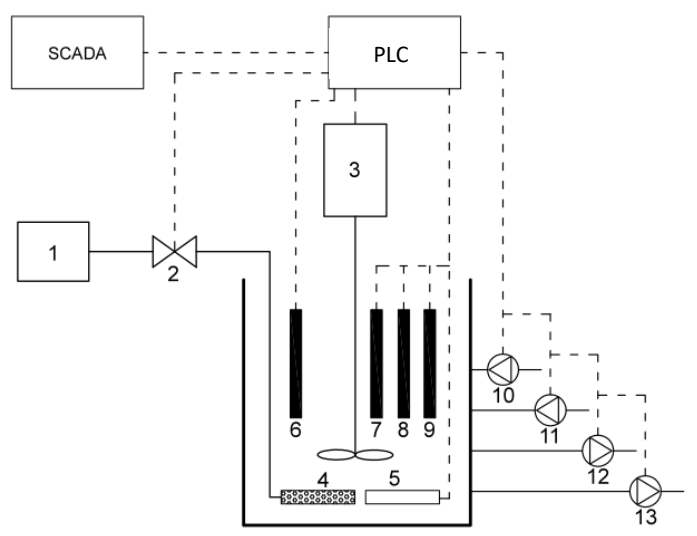

$$
\begin{aligned}
& 1 \text { - blower } \\
& 2 \text { - regulation valve } \\
& 3 \text { - mixer } \\
& 4 \text { - membrane plate diffuser } \\
& 5 \text { - heater } \\
& 6 \text { - AN-ISE } \mathrm{NH}_{4} / \mathrm{NO}_{3} \text { probe } \\
& 7 \text { - DO probe } \\
& 8 \text { - pH/REDOX probe } \\
& 9 \text { - hydrostatic probe } \\
& 10 \text { - influent pump } \\
& 11 \text {-pH control pump } \\
& 12 \text { - excess sludge pump } \\
& 13 \text { - effluent pump }
\end{aligned}
$$

Fig. 1. Pilot scale SBR set-up.

\subsubsection{Reactor for alpha factor measurements}

Aware of disadvantages for alpha factor determination in such small scale SBR, further verification test series were performed in reactor considered as more suitable for such tests. Cylindrical reactor $(0.315 \mathrm{~m}$ diameter and $2.0 \mathrm{~m}$ maximal depth) was used to reduce potential surface aeration and provide bigger depth. Reactor was equipped with single fine pore membrane diffuser (self-made) located at its bottom, connected to a blower. Air flow was measured using a rotameter and regulated by a ball valve. DO and temperature monitoring was provided by two DO probes. To prevent excessive surface aeration, tests were conducted in two ways: with or without cover preventing such phenomenon to compare results. For each measurement series, operation of start-up SBR was stopped at the end of the cycle and mixed liquor was transferred to alpha measurement reactor. After each series, mixed liquor was transferred back to SBR and normal operation restarted. Collected data was used to calculate $\mathrm{K}_{\mathrm{L}} \mathrm{a}$ values of analysed medium using MS Excel datasheet and compared to $\mathrm{K}_{\mathrm{L}} \mathrm{a}$ value determined in calculated from clean water tests, performed in the same conditions prior to shortcut nitrification start-up. All alpha factor measurements and data interpretation was performed according to ATV M 209E [5]. 


\subsubsection{Medium characteristics}

Pilot installation treated real reject water from a belt press without flushing water used for belt cleaning to avoid supernatant dilution. Dewatered sludge was after mesophilic digestion (HRT about 40d). Due to intermittent operation of belt press, leachate was collected periodically in a storage tank to provide supplies of influent medium for SBR. After filling, medium composition was determined. During start-up period, typical influent ammonium concentration, and alkalinity were equal $660 \mathrm{~g} \mathrm{~N}-\mathrm{NH}_{4} / \mathrm{m}^{3}$ and $56 \mathrm{~g} \mathrm{CaCO}_{3} / \mathrm{m}^{3}$, respectively.

\subsubsection{Analytical methods.}

Collected samples were filtered with syringe filters, pore size $1.2 \mu \mathrm{m}$ and after that ammonia, nitrite and nitrate nitrogen concentrations were measured using Hach photometric cuvette tests: LCK303 (2-47 mg N-NH $\left.4 / \mathrm{dm}^{3}\right)$, LCK342 (0.6-6 mg N-NO $\left./ \mathrm{dm}^{3}\right)$ and LCK340 (5-35 mg N-NO $3 / \mathrm{dm}^{3}$ ) and a DR3900 spectrophotometer.

\subsection{Shortcut nitrification start-up strategy}

Main goal of process start-up was to achieve stable and long-lasting inhibition of nitrite oxidizing bacteria (NOB) in fully nitrifying activated sludge taken from main treatment line. Final process parameters considered as start-up success were assumed as over $95 \%$ dominance of nitrite in sum of oxidized N-compounds. Start-up strategy was adapted from literature [6] and based on selective NOB inhibition by free ammonia concentrations due to high $\mathrm{pH}$ (7.7) and elevated $\mathrm{N}-\mathrm{NH}_{4}$ concentrations along with short SRT ( $\sim 3$ days) and low DO levels $\left(<1 \mathrm{~g} \mathrm{O}_{2} / \mathrm{m}^{3}\right)$.

\section{Results and discussion}

\subsection{Shortcut nitrification performance during start-up.}

Start-up was performed based on conventional activated sludge sample collected from the same WWTP as treated reject water. Nitrogen loading rate (NLR) was adjusted daily by the operator based on performed ammonia uptake rate tests (AUR) and composition of the reactor effluent, measured daily. Initial NLR was $0.2 \mathrm{~kg} \mathrm{~N}-\mathrm{NH}_{4} \cdot\left(\mathrm{m}^{3} \cdot \mathrm{d}\right)^{-1}$ and during next days of reactor operation was successfully increased as sludge enrichment with nitrifiers developed, allowing to double this value within 16 days. NLR decrease observed in days 4-6 was necessary to re-establish reactor operation stability due to excessive ammonium accumulation. Selected operating conditions (see section 2.2), allowed to successfully inhibit NOB activity, as nitrite presence in the effluent was decreasing until day 10. Since then, average nitrite accumulation rate $\left(\mathrm{N}-\mathrm{NO}_{2} / \mathrm{N}-\mathrm{NO}_{\mathrm{x}}\right.$ ratio $)$ was $96.8 \pm 1.9 \%$ what clearly indicates practically complete suppression of nitrite oxidation. As ammonium oxidation was almost complete (average $97.5 \pm 1.9 \%$ ) during the whole start-up, free ammonia inhibition occurred only partially during the SBR cycle, which suggests that other selection factors had huge impact on NOB wash-out process. 


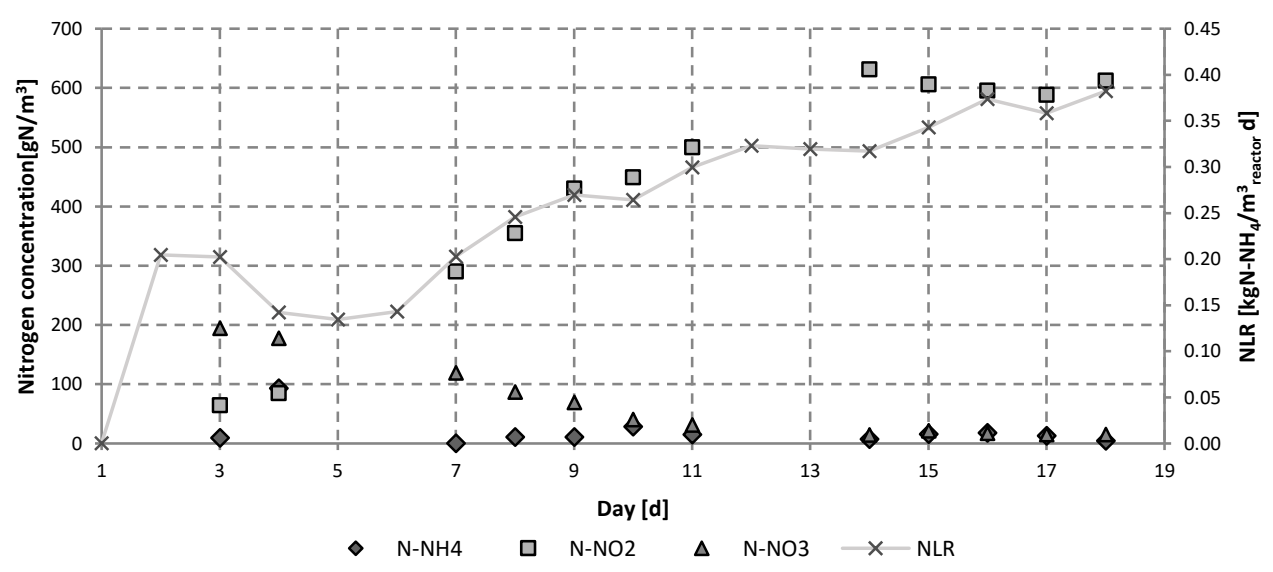

Fig. 2. Shortcut nitrification start-up.

\subsection{Alpha measurements during the start-up.}

Prior to shortcut nitrification start-up, series of clean water tests were conducted to determine $K_{L} a_{c w}$ value. After that, next measurements were performed using mixed liquor from the shortcut nitrification reactor.

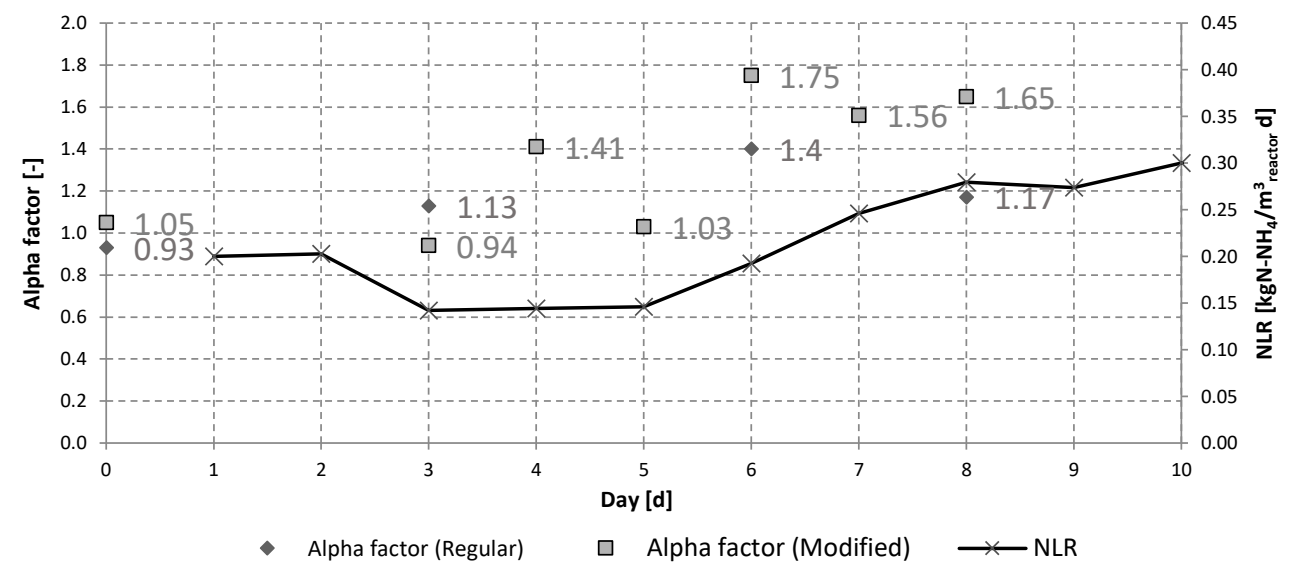

Fig. 3. Alpha factor during start up of Shortcut nitrification process.

Alpha factor measured in all tests, were close to 1.0 or above (Figure 3), which means that oxygen transfer efficiency in these conditions was similar or higher than in clean water. Such phenomenon is commonly known for different aeration devices than fine bubble diffusers (used in this study), such as coarse bubbles diffusers, jets and surface aerators. These aeration systems, providing high energy density and turbulent flow may locally affect mass transfer which may explain achieving higher alpha values [4,7] however, reactor size, geometry used and air flow rate used during measurements presented in this study were selected to minimize this effect observed previously in studies performed in small vessels $[8]$. 


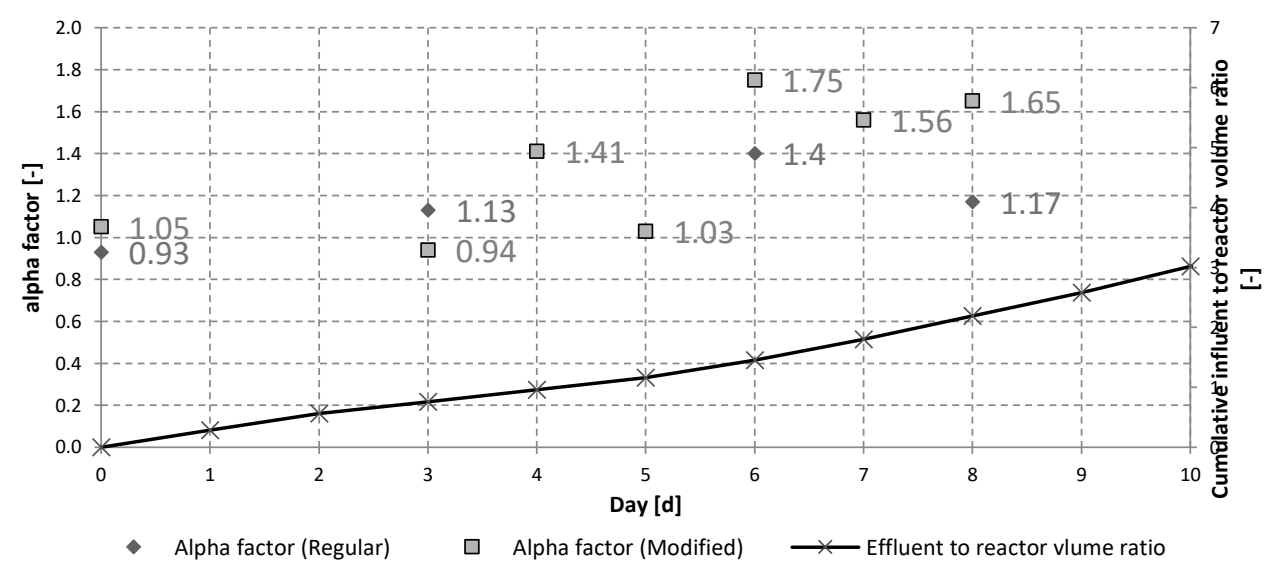

Fig. 4. Measured alpha values and cumulative influent to reactor volume ratio.

Except high alpha values observed at the beginning of the experiment, also its growth was noticed in further days as the process start-up developed, both in measurements conducted with or without the reactor cover. Some influence on this phenomenon had concentration of surfactants in the start-up reactor, as sludge inoculum collected from the mainstream reactor might contained these substances. As surfactants impact on alpha value is known, reject water influent, as a treated medium could led to constant dilution and finally washout them from the reactor. Measured alpha values and cumulative influent to reactor volume ratio is presented in Figure 4. Another potential aspect of observed changes is presence of organic polyelectrolyte in the reject water. Polyelectrolyte is used to improve sludge dewatering efficiency and its presence may lead to influence viscosity of the mixed liquor which determines resistance the bubble experiences when travelling and thus increase observed alpha value [9].

Despite these observations, lack of information about aeration systems in sidestream treatment facilities and impact of reject water composition on oxygen transfer efficiency creates need of further research should be focused on those directions. As aeration is the main operational cost of reject water treatment, guidelines for proper design should prepared to maximize benefits of sidestream treatment implementation.

\section{Conclusions}

- As sidestream treatment becomes more popular way to improve WWTP efficiency, knowledge about proper design of aeration systems in such reactors seems insufficient and may vary from guidelines known for municipal wastewater.

- Alpha factor determined in mixed liquor during shortcut revealed values higher than 1.0 which seems unlikely for fine bubble aeration diffuser tested in this study. Surprisingly, variability of this parameters value was observed, from 0.93 to 1.40 through start-up performance.

- Observed phenomenon is most likely result of reject water composition, especially lack of surfactants and presence of polyelectrolyte, which affects the viscosity of mixed liquor as alpha value change can be probably related to cumulative washout of substances from sludge inoculum due to reject water influent. Nevertheless, further investigation of these assumptions must be done. 


\section{References}

1. E. Pittoors, Y. Guo, S. W. H. Van Hulle, CHEM. ENG. COMM, 201, 983-1002 (2014)

2. J. Mueller, W. Boyle, J. Popel, Aeration: Principles and Practice CRC PRESS (2002)

3. B. Wett, WATER SCI TECHNOL, 56, 81-88, (2015)

4. D. Rosso M. K. Stenstrom, WEFTEC, 1, 4853-4863, (2006)

5. ATV M209E Measurement of the Oxygen Transfer in Activated Sludge Aeration Tanks with Clean Water and in Mixed Liquor, ATV (1996)

6. C. Antileo, A. Werner, G. Ciudad, C. Munoz, C. Bornhardt, D. Jeison., H. Urrutia BIOCHEM. ENG. J. 32, 67-78, 2006

7. M. Stenstrom R. Gilbert, WATER RES, 15, 643-654, (1981)

8. H. J. Hwang, M.K. Stenstrom The Effect of Surface Active Agents on Oxygen Transfer, UCLA-ENG-79-30, University of California, Los Angeles. (1979)

9. Amaral, O. Schraa, L. Rieger, S. Gillot, Y. Fayolle, G. Bellandi, Y. Amerlinck, S. T. Mortier, R, Gori, R. Neves, I. Nopens WATER SCI TECHNOL, 75, 507-517 (2016) 